\title{
Satellite-derived geoid for the estimation of lithospheric cooling and basal heat flux anomalies over the northern Indian Ocean lithosphere
}

\author{
S RAJESH ${ }^{1}$ and T J MAJUMDAR ${ }^{2, *}$ \\ ${ }^{1}$ Wadia Institute of Himalayan Geology, Dehradun 248 001, India. \\ ${ }^{2}$ Space Applications Centre (ISRO), Ahmedabad 380 015, India. \\ *Corresponding author.e-mail: tjmajumdar@rediffmail.com
}

The northern Indian Ocean consists of older Bay of Bengal (BOB) oceanic lithosphere with numerous intra-plate loads; whereas, contrasting elements like active Mid-Ocean ridge divergence and slow spreading ridges are present in the relatively younger $(<60 \mathrm{Ma})$ Arabian Sea oceanic lithosphere. The mechanism of lithospheric cooling of young age oceanic lithosphere from the moderately active and slow spreading Carlsberg Ridge is analysed by considering the hypothesis of near lithospheric convective action or whole upper mantle convection. We addressed these issues by studying the marine geoid at different spatial wavelengths and retrieved and compared their lithospheric cooling signatures, plate spreading and distribution of mass and heat anomalies along with seismicity, bathymetry, gravity and isochron age data. Results show that progressive cooling of young-aged oceanic lithosphere from the MidOcean Carlsberg Ridge is because of conductive cooling and those signals are retrieved in the shorter wavelength band $(111<\lambda<1900 \mathrm{~km})$ of constrained residual geoid with mass anomaly sources near to sublithospheric. This shows steadiness in the geoid anomaly decay rate $(\sim-0.1 \mathrm{~m} / \mathrm{Ma})$, consistency in the growth of thermal boundary layer and progressive fall of basal temperature and heat flux (900$300 \mathrm{~K}$ and $100-18 \mathrm{~mW} \mathrm{~m}^{-2}$ ) with increase of lithospheric age. The above observations are attributed to the fact that the advective-convective action beneath the Mid-Ocean Carlsberg Ridge is driven by the basal temperature gradient between the lithosphere and the near lithospheric low viscose thin layer. But, for the case of old-aged oceanic lithosphere in the BOB, the residual geoid anomaly cooling signals are not prominently seen in the same band as that of the Arabian Sea because of the Ninetyeast Ridge magmatism. However, its cooling anomaly signatures are retrieved at relatively higher band $(1335 \leq \lambda \leq$ $3081 \mathrm{~km}$ ) having erratic geoid decay rates $(-0.3$ to $0.2 \mathrm{~m} / \mathrm{Ma})$ owing to vigorous convective thermal instabilities originated around $290-530 \mathrm{~km}$ from the plume remnant in the upper mantle (for the case of the BOB). We discussed that such instabilities had transported sufficient heat energy to accelerate the erstwhile fast movement of the Indian Plate prior to the India-Eurasia continent-continent collision.

\section{Introduction}

The northern Indian Ocean lithosphere underwent various geodynamic processes since its earlier breakup from the greater Gondwanaland (Royer et al. 1989; Ramana et al. 1992). It consists of two different oceanic lithospheres, namely the Bay of Bengal (BOB) and the Arabian Sea situated at the east

Keywords. Lithospheric cooling; basal heat flux; northern Indian Ocean; multiple wavelength geoid; altimeter; Bay of Bengal. 
and the west of the peninsular India, respectively. The BOB oceanic lithosphere is relatively older and impregnated with aseismic intra-plate hotspot traces like the Ninetyeast Ridge, the $85^{\circ} \mathrm{E}$ Ridge and numerous fracture zones with an active Sunda-Andaman-Nicobar ocean trench subduction zone system (Curray et al. 1982; Rao et al. 1997; Subrahmanyam et al. 1999; Krishna et al. 2001; Rajesh et al. 2015). These are strikingly different from the tectonic elements that are present in the Arabian Sea lithosphere, where plate divergence process is more dominant all along the Carlsberg Ridge, the central Indian Ridge with Rodriguez triple junction amidst numerous fracture zones (Dietz and Holden 1970; Ramana et al. 1992; Chatterjee et al. 2007). In this work, a comparison between relatively younger Arabian Sea and the older BOB oceanic lithospheres has been made to understand their heat anomaly sources that derived from the marine geoid, and hence explained their lithospheric cooling with progression of age. Specifically, we attempted to unravel the nature of source and heat gain or lose mechanism that leads to slow plate divergence of young Mid-Ocean Carlsberg Ridge. And secondly, the characteristics of geoid anomaly with the progressive cooling of young Arabian Sea and the oldaged BOB oceanic lithospheres; and how they are linked to the past plate dynamics and depth to the anomalous body has been studied. Relating geoid anomalies with heat flux of oceanic lithosphere would also help to ascertain the earlier fast movement (Patriat and Acache 1984; Klootwijk 1984) of the Indian Plate during the middle Cretaceous prior to the India-Eurasia collision (Dietz and Holden 1970).

Being gravitational equipotential surface, the satellite altimeter-derived geoid and its residual geoid anomaly components over the northern Indian Ocean are obtained through spherical harmonics filtering from the observed geoid. Cazenave et al. (1983) have extracted the thermal parameters of the oceanic lithosphere as estimated from the geoid height data. Wei and Sandwell (2006) used the global isochron and bathymetry data to estimate the heat flow of the Cenozoic ocean basins. Parsons and Sclater (1977) deduced a linear relationship between the heat flow and bathymetry with lithospheric age. The proximity of residual geoid with earth's internal thermal and mass distribution processes and its correlation with bathymetry and lithospheric age were used to constrain (in terms of harmonic degree, anomaly wavelength and anomaly depth) and derive the lithospheric cooling signals of geoid from the observed geoid. These cooling geoid anomaly signatures are obtained for the young-aged oceanic lithosphere from the spreading Carlsberg Ridge (Chatterjee et al. 2007), where its activity has been studied using seismicity data, spreading rate variation and the location of existing hydrothermal vents.

The observed geoid anomaly in the northern Indian Ocean is dominated by long spatial wavelength anomalies like the Indian Ocean Geoidal Low (IOGL) (Chase 1979; Mahadevan 1994) and whose source depth lies at the lower mantle region. These anomalies were removed from the observed geoid anomaly and obtained the residual anomaly components related with upper mantle and lithospheric processes such as plate cooling, mass accumulation, basal heat flux estimation and gradient in the thermal boundary layer, etc. For youngaged oceanic lithosphere in the Arabian Sea basin, the basal heat flux computed from the constrained cooling signatures of the residual geoid anomaly from the Mid-Ocean Carlsberg Ridge is in the relatively shorter geoid wavelength band $(111<$ $\lambda<1900 \mathrm{~km})$ at shallow depth $(17-335 \mathrm{~km})$, even extended up to the oceanic crust. Presence of shallow anomaly sources, steadiness in the geoid anomaly decay rate, consistency in the growth of thermal boundary layer and a plausible mechanism of near lithospheric mantle convective action are considered in explaining the conductive heat loss which lead to steady lithospheric cooling of younger oceanic basins.

However, for old-aged oceanic lithospheres (>40 Ma) both in the Arabian Sea and in the BOB, the geoid anomaly decay rates are erratic. Moreover, it is also observed that the residual geoid cooling signatures are retrieved at relatively larger wavelength band $(1335 \leq \lambda \leq 3081 \mathrm{~km})$ with deeper (219-531 km) anomaly source entirely confined to the upper mantle region. Particularly in the BOB lithosphere, where we explained that deeper anomaly source in the upper mantle region with large wavelength geoid anomaly arise due to mass concentration of the Kerguelen magmatism (Rajesh and Majumdar 2014). The mass concentrations caused erratic thermal boundary layer and geoid anomaly rate, which signifies whole upper mantle convective action. The convective action caused accelerated movement of the old BOB lithosphere prior to the India-Eurasia collision, which in turn adversely affected the normal plate spreading and conductive cooling (Rajesh et al. 2015).

\subsection{Objectives}

- To understand lithospheric thermal processes of young- and old-aged oceanic lithospheres in the northern Indian Ocean, such as the Arabian Sea and the Bay of Bengal respectively, through the analysis of different wavelength band geoid; and hence to infer their past lithospheric dynamics and anomalous heat sources. 
- To study the progressive cooling of young-aged oceanic lithosphere from the divergent Mid-Oceanic type Carlsberg Ridge through the estimation of basalt heat flux anomalies and vertical temperature structure retrieved from the dynamically-constrained multiple wavelength geoid anomalies.

\section{Study area and data sources}

The area that has been selected for lithospheric investigation is the northern Indian Ocean in the Indian Tectonic Plate that consists of both the Arabian Sea and the BOB oceanic lithospheres. Study area ranges from $0^{\circ}$ to $25^{\circ} \mathrm{N}$ and $55^{\circ}$ to $100^{\circ} \mathrm{E}$.

In this study, we have used: (i) Geosat Exact Repeat Mission (ERM) data of one year with a repeat period of 17.6 days; (ii) Two datasets of ERS-1/2 satellites in the ocean mode measurements; in which, one set of data is from the geodetic phase of the ERS-1 with 168-day repeat orbit period with approximately $16 \mathrm{~km}$ track spacing and the other is ERS-2 of 35-day repeat orbit period with $80 \mathrm{~km}$ track spacing at the equator. The ERS-1 geodetic data consists total 165 tracks which falls over the whole northern Indian Ocean ranging from $0^{\circ}$ to $25^{\circ} \mathrm{N}$ latitude and $55^{\circ}$ to $105^{\circ} \mathrm{E}$ longitude; (iii) The third set of data used is the merged one year TOPEX/POSEIDON data obtained from the Physical Oceanography Distributed Active Archive Center (PODAAC), USA. Based on GEOS3/Seasat altimeter data, Rapp (1986) has generated gravity data from global sea surface height measurements. Later, Sandwell and Smith (1997) and Andersen et al. (2010) have also generated high resolution global gravity data from GEOSAT geodetic and ERS-1 missions. Details of data processing have been discussed elsewhere (Majumdar et al. 1998; Rajesh and Majumdar 2003, 2009, 2010). Apart from altimetric data, we have also used bathymetry data from the global one-minute grid of Smith and Sandwell (1997). Isochron of the study area to find young- and oldaged lithospheres with resolution of $1 \mathrm{Ma}$ is obtained from the data set of digital isochrons of the world's ocean floor from Muller et al. (1997). Seismicity data as hypo-central distribution over the active mid-oceanic spreading centres of the Carlsberg Ridge were obtained from the reviewed catalogues of International Seismological Centre (ISC-GEM catalogue, Storchak et al. 2013) for the period 1985-2009. Locations of active and inactive hydrothermal vents and corresponding halfspreading rates were obtained from the InterRidge vents database ver. 3.2 (Beaulieu 2013).

\section{Methodology}

\subsection{Extraction of multiple wavelength residual geoid anomalies}

In the context of extraction methodology, it is imperative to explain the need of multiple wavelength residual geoid anomalies to understand the lithospheric processes. Geoid anomalies computed

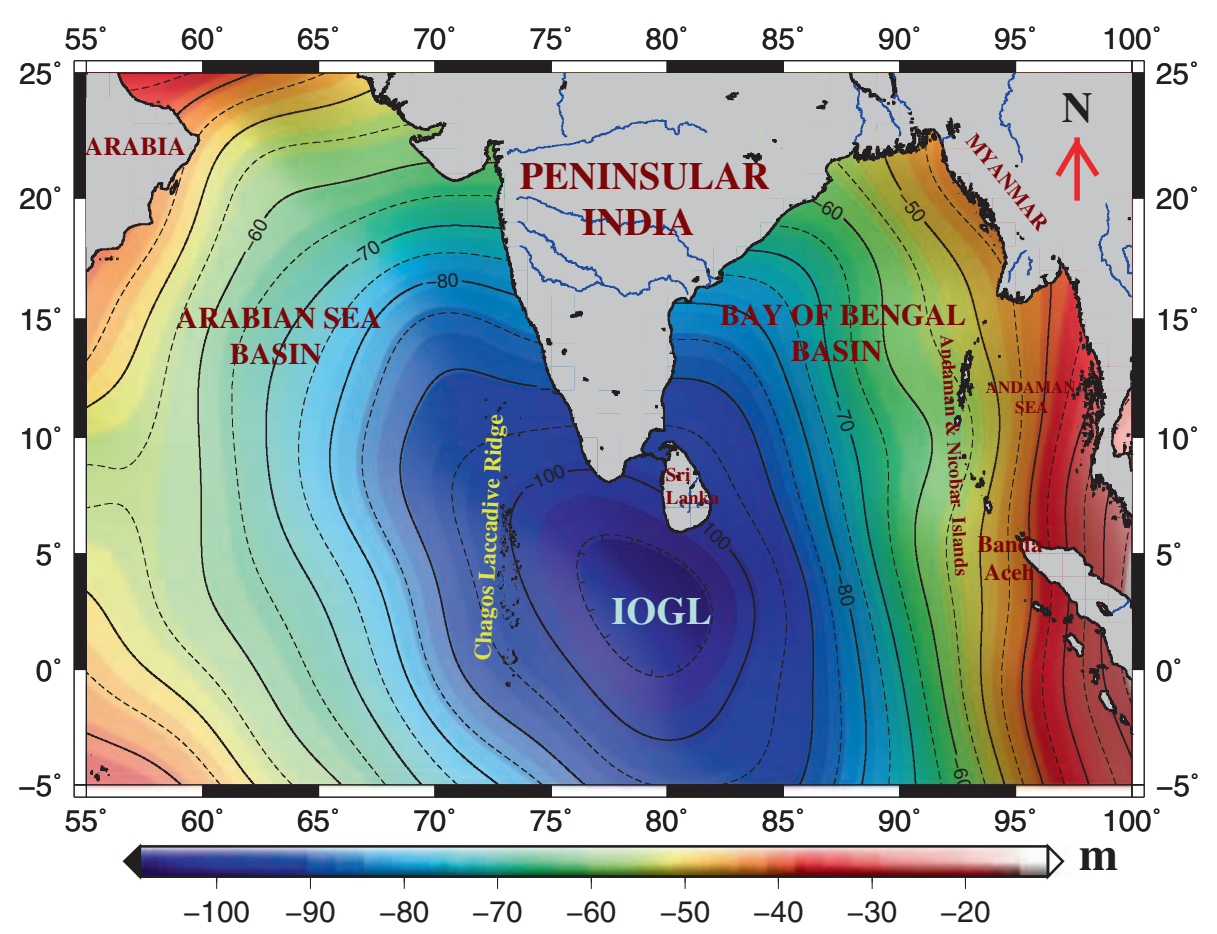

Figure 1. The long wavelength classical geoid anomaly over the northern Indian Ocean with the largest geoid anomaly low over the earth marked as IOGL. 
over the study area from the altimetric instantaneous sea surface heights were subjected to all environmental and bias corrections, as shown in figure 1. These anomalies are called classical geoid anomalies, which ranges from -110 to $-25 \mathrm{~m}$, and having anomaly half-spatial wavelength $>4500$ $\mathrm{km}$. The source of such a strong anomaly low geoid is shown as 'IOGL' (Chase 1979; Mahadevan 1994) lies deep in the earth's core-mantle boundary. Hager et al. (1985) studied such long wavelength anomalies and observed that viscous flow in the core-mantle boundary caused long wavelength deformation and hence, the long wavelength geoid. However, lithospheric processes such as plate cooling, effect of plate rotation as well as crustal mass accumulation are mainly produced by the shallower mass anomaly structures. Doin et al. (1996) used geoid anomalies to identify mass anomaly structures in the continental and oceanic regions. As a thumb rule, it is easy to interpret classical geoid anomalies as the resultant geoid anomaly produced by the scalar combination of short spatial wavelength geoid anomalies of shallow density structures with its long wavelength component of deeper source origin. Thus, by analyzing residual geoid anomalies at different wavelength bands through the disintegration of the classical geoid anomaly into its constituents could help to correlate easily with other geological observations on lithospheric plate spreading, crust-mantle mass accumulation, seismicity, bathymetry, heat anomalies and isochron ages, etc.

Theoretically, earth's gravitational field is represented by a set of spherical harmonic coefficients. And in effect, these harmonic coefficients are analogous to Fourier coefficients, but different in the sense that they are expressed over a spherical earth surface as solutions to Laplace equation. The geoid is a potential surface and its anomaly can also be expressed as a distribution over a unit sphere. Heiskanen and Moritz (1967) have expressed the geoid in terms of the fully-normalized spherical harmonic coefficients of degree $n$ and order $m$ with the normalized associated Legendre functions. The geoid $(N)$ is:

$$
\begin{aligned}
N(\phi, \theta)= & \frac{G M}{R} \frac{1}{g_{0}} \sum_{n=2}^{\infty} \sum_{m=0}^{n}\left(\frac{a_{e}}{R}\right)^{n} \\
& \times\left[C_{n m} \cos m \theta+S_{n m} \sin m \theta\right] \\
& \times P_{n m}(\sin \phi),
\end{aligned}
$$

where ' $M$ ' is the mass of the earth, ' $R$ ' is the radius at the location of calculation, ' $a$ ' ' is its equatorial radius and ' $g_{0}$ ' is the normal gravity, 980 $\mathrm{cm} \mathrm{s}^{-2}$. Notations ' $\phi$ ' and ' $\theta$ ' are the geocentric latitude and longitude, respectively at the point of calculation. ' $C_{n m}$ ' and ' $S_{n m}$ ' are the fully-normalized spherical harmonic coefficients of degree ' $n$ ' and order ' $m$ '. The reference is ellipsoidal earth. The normalized associated Legendre function is $P_{n m}(\sin \phi)$, and when the non-negative integer $m$ equal to zero, then the normalized Legendre function becomes a Legendre polynomial $P_{n 0}(\sin \phi)$. When $n=0$, the corresponding potential function becomes $U=G M / R$, which is the mean gravitational potential of the spherical earth. Each term after the mean value represents a harmonic deviation from the mean value. The magnitude of ' $C_{n m}$ ' and ' $S_{n m}$ ' are the mass distribution functions. So when there is a mass excess, the potential goes positive with respect to the mean value, while if there is a mass deficiency, then the latter becomes negative. Similarly, the gravity anomaly $(\nabla g)$, which is the first derivative of the potential can also be written in terms of $C_{n m}, S_{n m}$ and $P_{n m}$ as:

$$
\begin{aligned}
g(\phi, \theta)= & \frac{G M}{R^{2}} \sum_{n=2}^{\infty} \sum_{m=0}^{n}(n-1)\left(\frac{a_{e}}{R}\right)^{n} \\
& \times\left[C_{n m} \cos m \theta+S_{n m} \sin m \theta\right] P_{n m}(\sin \phi) .
\end{aligned}
$$

For each degree ' $n$ ' there are $m=0$ to $n$ orders. The harmonic degree ' $n$ ' can correspond to spatial wavelength ' $\lambda$ ' of the geoid signal, which can be obtained from the circumference of the concerned spherical body. For such a body, the equivalent wavelength corresponds to harmonic degree ' $n$ ' which can be expressed as:

$$
\lambda=2 \pi R / n \text {. }
$$

For the case of earth with spherical body assumption, the circumference comes around 40,000 km. Thus, for a harmonic of $n=2$, the wavelength comes around $20,000 \mathrm{~km}$. Thus, the higher harmonics of ' $n$ ' would not only shift the geoid power spectrum, as computed from the coefficients ' $C_{n m}$ ' and ' $S_{n m}$ ', to a low amplitude but also into the lower

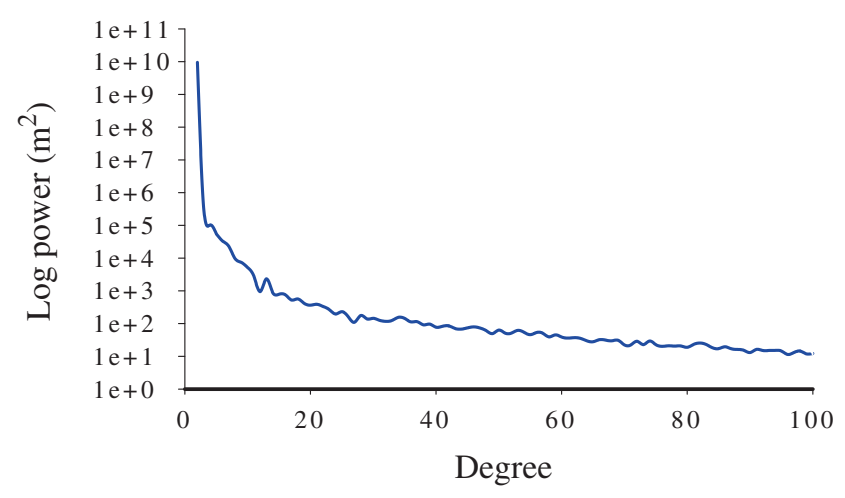

Figure 2. The geoid power spectrum shown as the power law. The spectral energy falls at higher harmonics or at shorter wavelength with respect to the lower harmonics of larger wavelengths. 
wavelength domain as shown in figure 2. Thus, based upon the degree harmonics and anomaly wavelength, the pass band geoid anomalies at different wavelengths of interest can be extracted after applying tapering windows to remove the pass band edge effects. However, above expressions are deficient to explain on what would be the depth to the source body for a particular wavelength band geoid; although, those expressions could explain the interrelationship between geoid anomaly wavelength, anomaly strength and degree harmonics.

\subsection{Relationship between anomaly wavelength,} degree harmonics and limiting point mass depth

The depth to the anomalous source can be obtained from the ratio of gravity to geoid anomalies above an anomalous structure with an assumption of a point mass body. Bowin $(1983,2000)$ and Bowin et al. (1986) have used ratios of gravity integrals and its derivatives with point mass assumption for calculation of the depth to the anomalous body. On the basis of that assumption, the limiting depth to the source body can be written as $z=\frac{g_{0}}{g / N}$, where ' $g$ ' and ' $N$ ' are the gravity and geoid anomalies distributed in a particular harmonic degree of the concerned point mass body. But the above expression lacks wavelength dependency of the anomalous signal with respect to the depth of the source body. The expression for depth to the source ' $z$ ', with the degree harmonic ' $n$ ' can be written as $z_{n}=R /(n-1)$, which explains the inverse dependency of degree harmonics and the source point mass depth. Here, ' $z_{n}$ ' is the limiting depth which corresponds to that particular degree harmonics ' $n$ '. ' $z_{n}$ ' is expressed in terms of wavelength using equation (3), shown in equation (4) and detailed in figure 3. The figure also depicts the wavelength dependency of earth's internal thermal processes with geoid anomaly wavelength, point mass depth and degree harmonics with locations of major mantle discontinuities and IOGL:

$$
z_{\lambda}=\frac{R \lambda}{2 \pi R-\lambda}
$$

Here, in case of earth, ' $\lambda$ ' could not be more than $2 \pi R=40,000 \mathrm{~km}$ which is the limiting wavelength. Thus, equation (4) indicates that for the case of extremely short wavelength topographic features, the limiting depth is less or rather insensitive compared to the larger wavelength topographic features.

\section{Results and discussion}

\subsection{Geoid undulation power spectrum and} correlation with earth's internal thermal processes

The observed geoid undulation over the region as shown in figure 1 shows the 'IOGL' anomaly, which

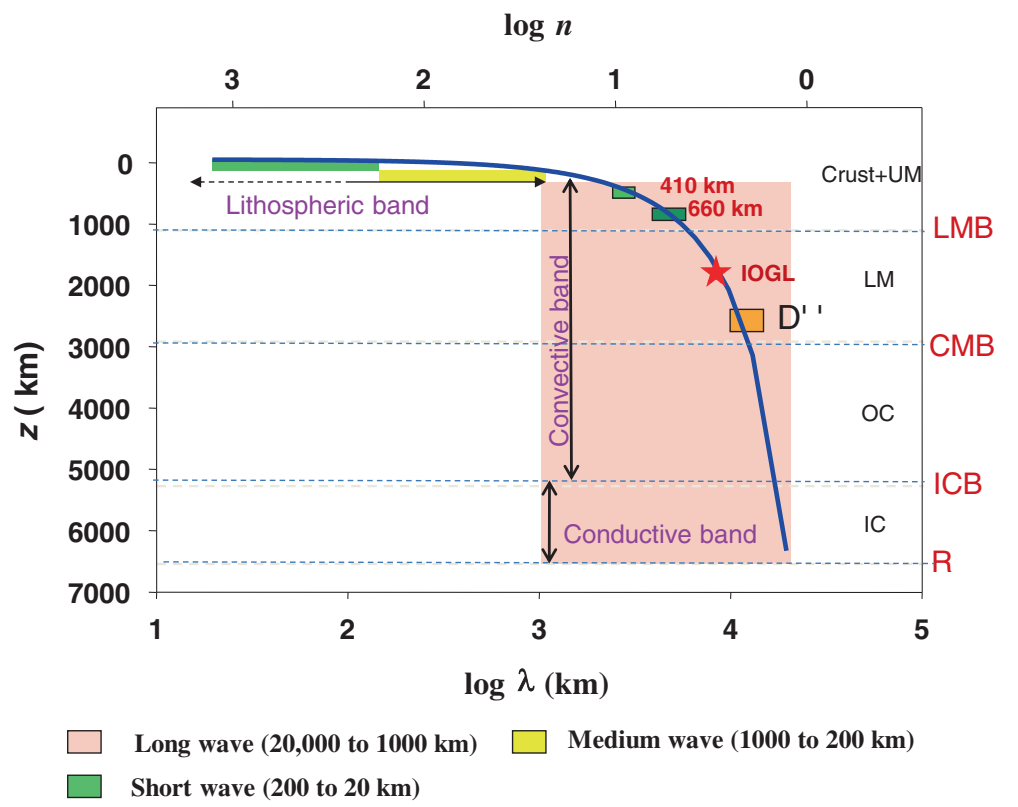

Figure 3. Earth's interior thermal processes and major density anomaly structures are shown in terms of degree harmonics $(n)$, anomaly wavelength $(\lambda)$ and point source depth $(z)$; modified after Rajesh (2009). The classification of geoid anomalies according to the wavelength (Torge 1989) is shown in green, yellow and red bands. The red star shows the IOGL point source depth in the upper mantle region. LMB: Lower mantle boundary; CMB: core mantle boundary; ICB: inner core boundary, R: radius of the earth; UM: upper mantle; LM: lower mantle; OC: outer core; IC: inner core. 
is the only dominating long wavelength component that subdued all other short wavelength geoid anomalies emanating from shallow density structures. As a result, geoid anomalies related with lithospheric cooling, crust-mantle density effects are not evident. Thus, the deeper effects in the overall observed geoid or the classical geoid has to be removed by computing the power spectral variation of the geoid. The power spectral variation of geoid undulation (shown earlier as figure 2) is obtained by computing the degree variances, ' $\sigma_{n}^{2}$ ' of the corresponding harmonics by using EGM96 (NIMA) coefficients (Lemoine et al. 1998) as sum of squares of $C_{n m}$ and $S_{n m}$ (DeLaughter et al. 1999). Figure 3 also explains how major density discontinuity anomalies in the mantle such as the $410 \mathrm{~km}, 660 \mathrm{~km}$ and the mantle ' $\mathrm{D}^{\prime \prime}$ ' (the discontinuity layer just $300 \mathrm{~km}$ above the core-mantle boundary) density anomalies are distributed with depth, harmonics degree and the anomaly wavelength. The slope of the curve changes sharply outside the lithospheric band owing to enhanced density structures that are related with the convective mantle and the conductive core thermal processes. Richards and Hager (1984) also correlated geoid anomalies with internal boundary deformation of discontinuities that related with whole body mantle convection. Thus, the 'IOGL' geoid undulation is of deeper origin and its signal energy is in the lower harmonics or in higher wavelength domain and at a point mass depth of $\sim 1800 \mathrm{~km}$ in the lower mantle (Rajesh 2009).

The power spectral variation (figure 2) up to harmonics 100 shows that most of the geoid undulation signal energy is in the lower harmonics or higher wavelength domain compared to the higher harmonic degree. The band from 2 to 10 harmonics corresponding to anomalies having wavelength range from 20,000 to $4000 \mathrm{~km}$, with the minimum point source depth of more than $700 \mathrm{~km}$. Thus, for 2-10 geoid anomaly harmonics, the source depth lies deeper than $660 \mathrm{~km}$ in the upper mantle; but above the lower mantle discontinuity. By carefully examining the power spectral plot, it is observed that between harmonics 2 and 5, the power falls very rapidly due to mass anomaly heterogeneities at depths more than $1500 \mathrm{~km}$ in the lower mantle region. Hager et al. (1985) and Ricard et al. (1993) have reported the lower mantle mass heterogeneities in the lower harmonic geoid of degree less than 10. Analysis of geoid anomaly over known geoid highs and lows over the globe at different harmonics by Bowin (2000) showed that, in the 2-10 degree range, the 2-3 degree contribution is more than $70 \%$. Also in the 2-10 degree package, the contribution from degree $5-10$ is not as intense as that of $2-5$, which can be observed in the reduced slope of the power fall. The 5-10 degree regime explains the mass heterogeneities at depth ranges between 700 and $1500 \mathrm{~km}$ in the lower mantle region. Most of the lower mantle mass anomaly structures or heterogeneities are mainly controlled by the viscosity of the lower mantle region which is almost an order of magnitude (King 2002) more than the viscosity of the upper mantle. Above degree 10 harmonics, the contribution of each harmonic is not so significant enough compared with the 1-10 range. Eventhough the power of amplitudes are less in above 10 degree range, the distinct boundaries of the density heterogeneities are maintained and this can be observed from the spectrum (in figure 2) as small oscillations or kinks. For example, to interpret the lithospheric scale processes, the residual geoid anomaly has to be extracted from the classical geoid anomaly by observing the small oscillations in the harmonic degrees 10,13 and 30. These oscillations can be used as markers to define the extraction window. These oscillations are not noise because not only the variation of its amplitude, but its power spectrum slope also changes.

\subsection{Residual geoid anomaly related with cooling of the northern Indian Ocean lithosphere}

Plate tectonic theory explains the formation of new oceanic lithosphere at the Mid-Oceanic region, where the hot magma ascends and erupts and then cools to form roppy and pillow lava structures due to its immediate contact with the sea water. The newly formed crust later got displaced away from the ridge spreading axis due to the ridgepush force; as a result, the new oceanic lithosphere becomes cooler, denser and denser, and finally subsides at greater depth. Thus, there is a decline in the heat flux of the oceanic lithosphere with maximum at the ridge axis to minimum values at greater distances or at greater lithospheric ages. We attempted to extract the gradual variation of lithospheric cooling from the Mid-Ocean ridge axis to the older lithospheric ages in the northern Indian Ocean lithosphere through the filtering of classical geoid and computed the average heat flux of the region.

In the northwestern Indian Ocean, the Carlsberg Ridge is an active Mid-Ocean type divergent plate boundary that separates Arabia and the Somalia plates as shown in figure 4(a). As the spreading takes place, young oceanic crusts are formed at the ridge axis. This is evident from the white contours of isochron ages, appeared near symmetrical at both sides of the ridge axis. The older crust was pushed away from the ridge axis to further north in the spread direction and shown as bold white arrows in the figure 4(a). Thus, in the Arabian Sea basin, the oldest oceanic lithosphere is around $90 \mathrm{Ma}$ and found close to the northwestern continental margin of peninsular India. At present, the 


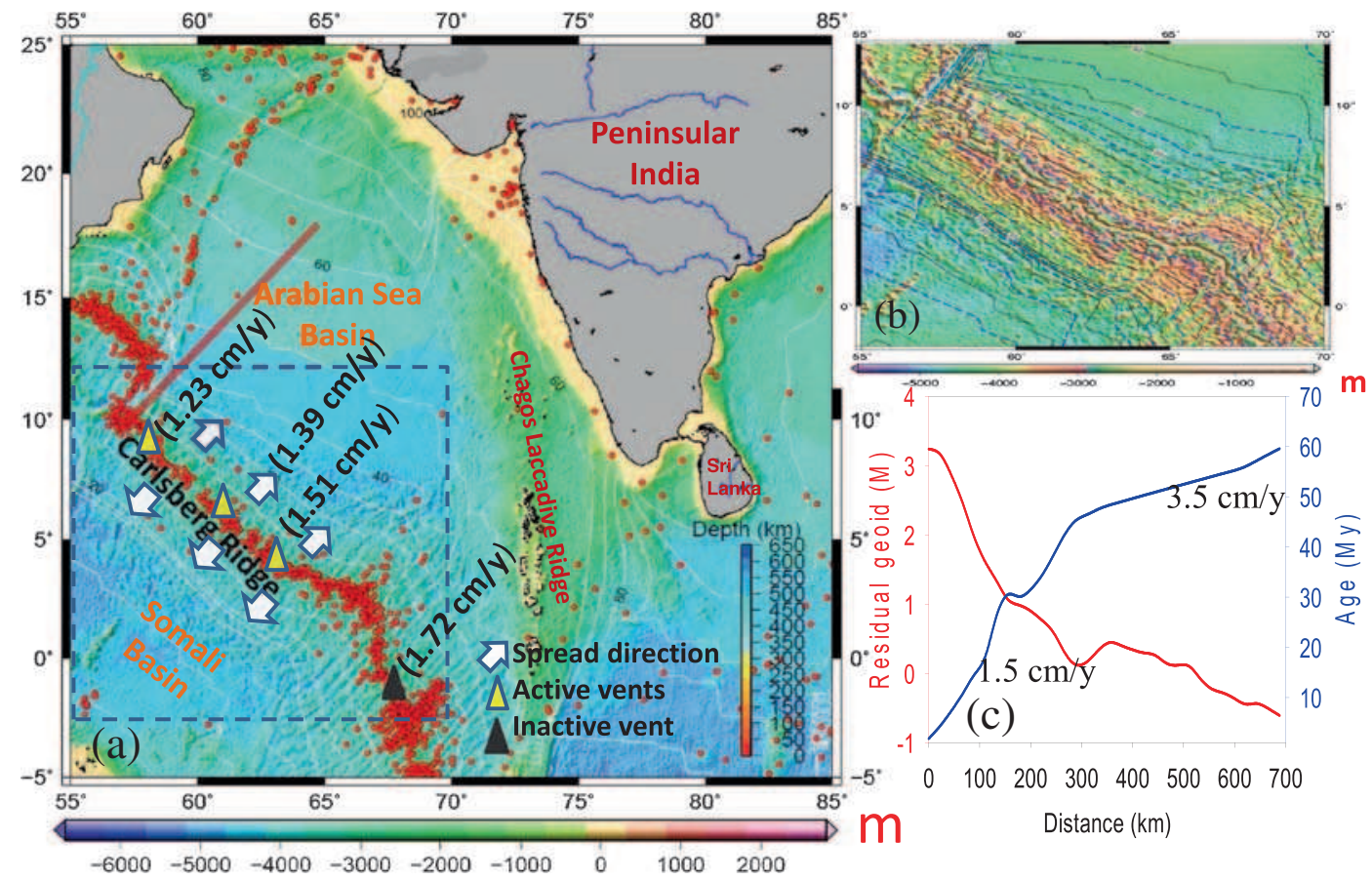

Figure 4. (a) shows the bathymetry of northwestern Indian Ocean with Carlsberg Ridge area marked in grey dotted-lined box. White contours are isochron ages of the ocean floor (Muller et al. 1997). Red dots are hypocentral locations (Storchak et al. ISC-GEM catalogue) of seismicity. White bold arrows show the NE-SW oriented Carlsberg Ridge spread direction. Yellow and black triangles are active and inactive hydrothermal vents along the axis of ridge, respectively. Bold red extended line is the location of profile as explained in (c). (b) shows the detailed bathymetry of the Carlsberg Ridge mentioned in the dotted box; highlights the ridge axial valley and the offsetting fracture zones. (c) The red line shows the fall of residual geoid anomaly from the ridge axis to greater off-axis distances. The blue line depicts the reduction in ridge spreading rate since $60 \mathrm{Ma}$ to present.

ridge segments are tectonically active as observed along the ridge axis seismicity and the presence of hydrothermal vents. Active hydrothermal vents are shown as yellow triangles, where the half spreading rate varies from 1.23 to $1.51 \mathrm{~cm} / \mathrm{y}$ towards the $\mathrm{SE}$ direction along the ridge strike. Majority of earthquakes occurred along the ridge axial valley are less than moderate magnitude and having hypocentral depths of around $10 \mathrm{~km}$. The NW-SE trend of hypocentral distribution along with the ridge bathymetry matches with the actual orientation of the ridge axial valley. The offset of ridge axial valley caused by NE-SW trending fracture zones at its summit is evident from the bathymetry and shown in figure 4(b).

In order to understand the heat flux variation related with formation of new oceanic lithosphere, the classical geoid anomaly has been de-trended in two different degree harmonics or wavelength bands as explained previously through spherical harmonic band pass filtering. The criteria that have been used for the selection of band is that anomalies are generally higher at the spreading Mid-Ocean ridge axis and hence a higher heat flux compared to the low heat flux values in the offspread axis region. In figure 4(c), the red line explains high residual geoid anomaly close to the spread axis, which gradually gets tapered as it moves away from the ridge axis to greater distances or lithosphere of older ages. Thus, the investigation was mainly focussed to include the low harmonics degree geoid anomaly; such that, the slowly varying nature of heat flux anomalies of the oceanic lithosphere are retrieved effectively in the residual geoid anomaly components. Pollack et al. (1993) estimated the mean heat flow over the oceans as $150 \mathrm{~mW} \mathrm{~m}^{-2}$ based upon the harmonic analysis of available experimental, theoretical and estimated data and expanded up to harmonics degree 12. However, the revised estimates of average heat flow over the oceans is around $60-80$ $\mathrm{mW} \mathrm{m} \mathrm{m}^{-2}$ based upon the high resolution heat flow data expanded up to harmonics degree 36 (Hamza et al. 2008), which is comparable with the estimation of Hofmeister and Criss (2005). Doin et al. (1996) have constrained the harmonics degree from 12 to 30 for a global gridded dataset for studying the thermal anomalies using geoid. But what is observed for the selection of harmonic band in the northern Indian Ocean lithosphere is slightly different from the harmonic band selected for the global data set. For the case of old oceanic lithosphere, like the BOB, the harmonic band 13-30 of classical geoid satisfies the criteria for selection; while 
for the case of young oceanic lithosphere, like the Arabian Sea, the required degree harmonics band is $21-360$.

Figure 5 shows the residual geoid anomaly that stands for the progressive cooling of young-aged oceanic lithosphere in the Arabian Sea basin for a wavelength band $111<\lambda<1900 \mathrm{~km}(21-360$ harmonic band). The anomaly magnitude is of $5.75 \mathrm{~m}$ high over the spreading Carlsberg Ridge with a spread direction shown as orange dashed symmetric arrows along NE-SW. Along the spread direction and away from the ridge axis in NESW direction close to the western continental margin of India (WCMI), the residual geoid goes to a minimum value of $-3.25 \mathrm{~m}$. The black contour lines are the isochron ages which progressively increase along the spread direction from the Carlsberg Ridge axis. Thus, for the Arabian Sea basin, the gradual fall of geoid anomaly with lithospheric age from the Carlsberg Ridge axis to its northern region reflects the progressive cooling of the lithosphere. However, for the case of BOB, the isochron ages are $>100 \mathrm{Ma}$, where the oldest lithospheres are found close to the eastern continental margin of peninsular India, and hence the same band anomaly $111<\lambda<1900 \mathrm{~km}$ is not showing the signals of progressive cooling. In this basin, the fall in geoid anomaly, which stands for the progressive cooling of the lithosphere, was expected towards the eastern continental margin of India (ECMI). It is also observed that in the eastern portion of the BOB basin, the geoid anomaly is as high as around $6 \mathrm{~m}$ over the aseismic Ninetyeast Ridge system in $\mathrm{N}-\mathrm{S}$ direction. The late intraplate magmatism associated with the formation of the Ninetyeast Ridge system from the Kerguelen hotspot (Mahoney et al. 1983; Rajesh and Majumdar 2014) had corrupted the geoid anomaly signals in the wavelength band $111<\lambda<1900 \mathrm{~km}$ (harmonics 21-360). This had affected the thermal cooling anomaly signatures associated with the normal plate spreading of the BOB basin. Thus, in order to get the cooling signals associated with normal plate spreading of the BOB basin, some of the short wavelength geoid anomaly features, emanated from relatively deeper mass density structures of the Ninetyeast Ridge, have to be eliminated. Moreover, it is known that mega lithospheric features like the Ninetyeast Ridge in the BOB have an average width of $300 \mathrm{~km}$ and its signatures have to be removed fully from the classical geoid for retrieval of the lithospheric cooling signatures.

The geoid anomaly related with progressive cooling of the BOB oceanic lithosphere was obtained in the wavelength band $1335 \leq \lambda \leq 3081 \mathrm{~km}$ (harmonics 13-30) of the classical geoid (figure 6). It is evident from the figure that the effect of the Ninetyeast Ridge system, a short wavelength noise, has been successfully removed to obtain the lithospheric cooling signal. It maintains only the anomalies of distinct wavelength band ranges from $1335 \leq \lambda \leq 3081 \mathrm{~km}$. Also, at the northern BOB, the lithospheric age is $>80 \mathrm{Ma}$, where the geoid anomaly is low in the corresponding wavelength band. Towards the southern BOB, the oceanic

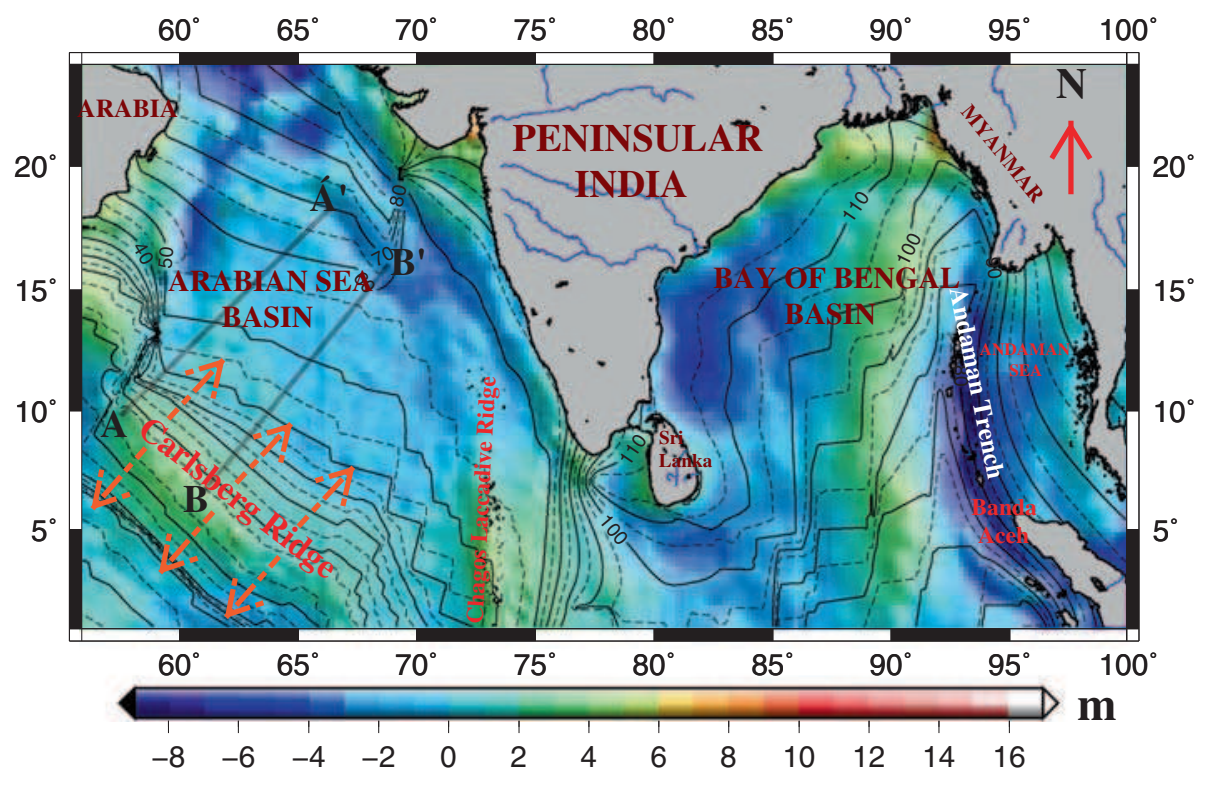

Figure 5. The residual geoid anomaly that stands for the progressive cooling of young age $(<45$ Ma) oceanic lithosphere in the Arabian Sea basin for a wavelength band $111<\lambda<1900 \mathrm{~km}\left(21-360\right.$ harmonic band). $\mathrm{AA}^{\prime}$ and $\mathrm{BB}^{\prime}$ are the locations of profiles where the geoid anomaly decay rate, thermal boundary thickness and heat flux anomalies are calculated. The isochron ages are shown as black contours. 


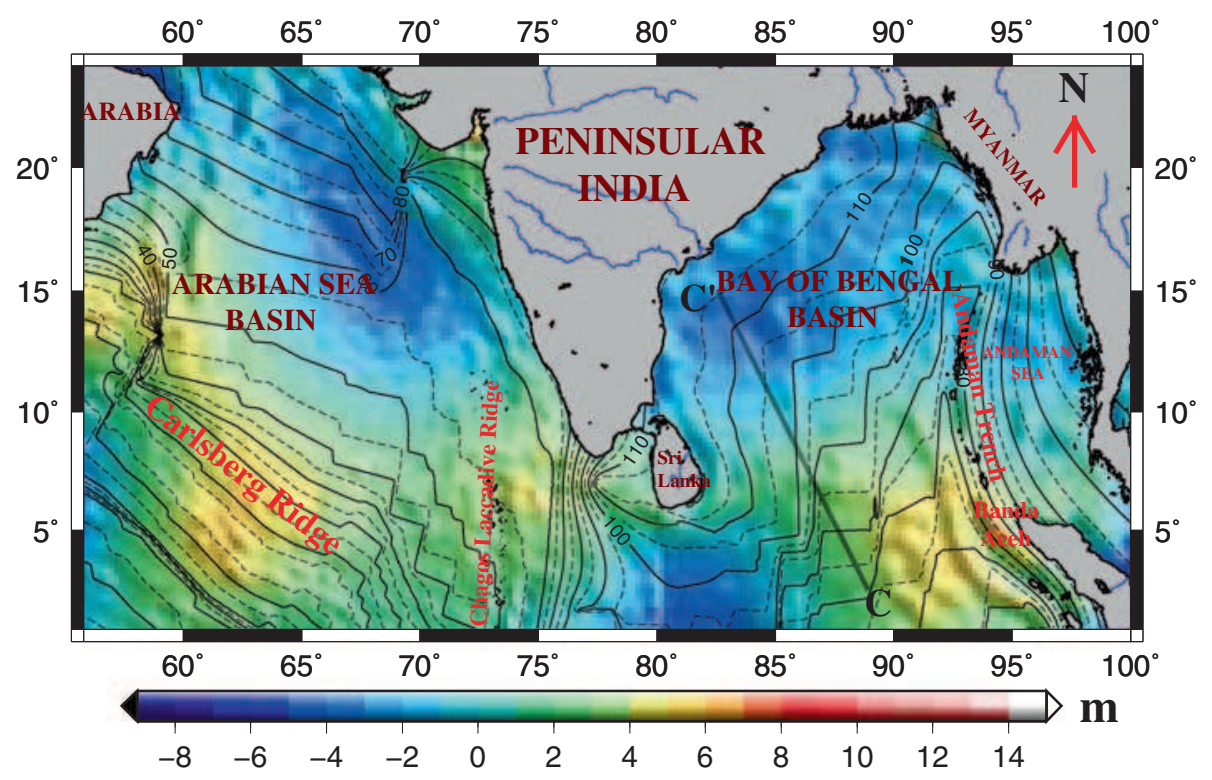

Figure 6. The geoid anomaly related with progressive cooling of the Bay of Bengal oceanic lithosphere were obtained in the wavelength band $1335 \leq \lambda \leq 3081 \mathrm{~km}$ (harmonics 13-30) of the classical geoid. $\mathrm{CC}^{\prime}$ is the location of profile where the geoid anomaly decay rate is retrieved towards older ages. The isochron ages are shown as black contours.

lithosphere is relatively young (60-70 My) and hence higher geoid value of around $6 \mathrm{~m}$ is maintained. In fact, the difference in geoid anomaly wavelength bands of the Arabian Sea and the BOB lithospheres towards plate cooling processes need to be analysed further in terms of difference in depth of their anomalous heat sources.

\subsection{Inference from the residual geoid anomaly on earlier fast $N-S$ movement of the BOB lithosphere and its deeper anomalous heat sources}

The difference in the residual geoid anomaly bands related with lithospheric cooling of the BOB and the Arabian Sea basins throws light on the hypothesis of earlier fast movement of the BOB oceanic lithosphere during the middle Cretaceous. Based on the marine magnetic anomaly (Ramana et al. 1992) lineations and their correlations, the concept of earlier fast spreading of the Indian Plate at almost $11 \mathrm{~cm} / \mathrm{y}$ was proposed. Moreover, from figure 4(c), it is evident (from the blue line) that from $60 \mathrm{Ma}$ to the present, the spreading rate of the Arabian basin was reduced from $3.5 \mathrm{~cm} / \mathrm{y}$ to the present day value of $1.5 \mathrm{~cm} / \mathrm{y}$. Thus, the trend shows prior to the India-Eurasia collision, the Indian plate moved towards the Eurasian Plate at a faster rate of more than $11 \mathrm{~cm} / \mathrm{y}$. This rate was subsequently reduced to the present day value followed by the IndiaEurasia continent-continent collision around $55 \mathrm{Ma}$ and consequent crustal under thrusting lead to the rise of the Himalayas. The greater wavelength band of the lithospheric cooling geoid anomalies in the $\mathrm{BOB}$ ranges $1335 \leq \lambda \leq 3081 \mathrm{~km}$ compared to the shorter wavelength cooling geoid anomalies of $111<\lambda<1900 \mathrm{~km}$ of the Arabian basin, indicating the earlier fast movement of the BOB basin (Rajesh and Majumdar 2003, 2009). This argument can be supported through the classic example of spreading of Mid-Oceanic Ridge margins of the Mid-Atlantic Ridge and the East Pacific Rise. The Mid-Atlantic Ridge is a slow spreading passive margin that caused the formation of very short wavelength Mid-Atlantic Ridge topography and hence the short wavelength lithospheric geoid; while the latter is a fast spreading ridge system in the Pacific Plate that caused the long wavelength topography and the long wavelength lithospheric geoid. Thus, the BOB was a Pacific type, fast spreading basin prior to the India-Eurasia continent-continent collision. However, the postcollision slow plate movement is evident in the Arabian Sea basin with slow spreading and hence belongs to the Atlantic type. Thus, the wavelength variation of the geoid anomaly can be used to decipher the pace of the basin movement.

In addition to the wavelength differences, the corresponding point mass depths, which are mainly the depths to the heat anomaly sources in the BOB and the Arabian basin, can be compared. In the $\mathrm{BOB}$, the depth to the point mass anomaly structure is more in the range of $219-531 \mathrm{~km}$, which is entirely confined to the upper mantle region. Hence, it can be termed as a relatively cool basin devoid of any spreading activity. Moreover, seismic Love and Rayleigh waves that form dispersion studies (Singh 1990), also favour a very low level mantle in the BOB. However, in the Arabian Sea basin, the depth to the point mass varies from 17 to 
$335 \mathrm{~km}$, even up to the shallow level of the oceanic crust. Through numerical modelling studies, Craig and McKenzie (1986) proposed the presence of thin low viscosity layer at the base of the lithosphere where small scale convective cells can be generated. Considering the prevailing tectonic scenario in the Arabian Sea basin, which has spreading activity and very shallow seismicity mainly along the Central Indian Ridge, the Carlsberg Ridge, and the southeast Indian Ridge, the magma sources definitely exist at a very shallower level of around 17 $\mathrm{km}$, beneath the ridge axis. Thus, by comparing the depth of their heat sources as well as slow plate spreading, it can be inferred that for the Arabian Sea basin, the near listhospheric heat sources might have aided the Carlsberg-Mid-Ocean centric convection processes. As a result, there might be effective cooling of the lithosphere due to the thickening of thermal boundary layer with the progression of lithospheric age. However, for the case of BOB, maximum point mass depth is around $531 \mathrm{~km}$, which is right at the centre of upper mantle region. The nature of the source is not near-lithospheric and non-spreading but definitely has an influence of mass concentration in the upper mantle region caused by the remanent of Kerguelen magmatism (Rajesh et al. 2015).

\subsection{Inference on thermal instabilities and heat flux calculation using residual geoid anomaly rate}

Observations on progressive cooling of the lithosphere and depth of heat anomaly sources from the Carlsberg ridge area in the Arabian Sea and the BOB basins, respectively, suggest: (1) for young age oceanic lithosphere, the source of Mid-Ocean plate divergence is from shallow near-lithospheric convective cells. The convective process is mainly controlled by the mass anomaly and temperature gradient between the lithosphere and the sub-lithospheric mantle in the low viscosity thin layer, (2) for old age oceanic lithosphere, the mass anomaly sources are at greater depth and often have a complicated heat loss and gain processes. Especially, when there are two possible sources, one that related with plume remnant and the other because of disparity in the convective and conductive heat gain and loss processes of the aged lithosphere. In such cases, at the base of the lithosphere, the presence of small-scale convection having spatial wavelength around 500 to thousands of kilometers brings heat apart from the plume remnant sources and hence causes a minor rise in the heat flux beneath the old oceanic lithospheres.

To quantify these possibilities, we studied the geoid decay rate along a few profiles across both the young Arabian Sea and the old BOB lithospheres. The geoid decay rate gives how fast the geoid anomaly gets reduced from the active source region in the young Mid-Ocean to the deeper and older oceanic lithospheres. This has been computed along a few profiles in both the wavelength ranges of $111<\lambda<1900$ and 1335 $\leq \lambda \leq 3081 \mathrm{~km}$ in the young and old lithospheric regions of the Arabian Sea and the BOB respectively, and shown in figure $7(\mathrm{a}-\mathrm{c})$. It is evident from figure $7(\mathrm{a}$ and $\mathrm{b})$ that variation in the residual geoid anomaly rates for young $(<45 \mathrm{Ma})$ oceanic lithosphere in the Arabian Sea basin is marginal. But at ages greater than $45 \mathrm{Ma}$, the residual geoid rate shows rapid fluctuations. The amplitude of this variation is more severe and rapid as shown in figure $7(\mathrm{c})$ for the case of even older lithosphere in the $\mathrm{BOB}$ at its respective wavelength band.

The steady variation of the residual geoid anomaly rate of around $-0.1 \mathrm{~m} / \mathrm{Ma}$ is an indication of the nature of heat loss or transmission that takes place in the young age oceanic lithosphere from the underlying sublithospheric mantle heat sources mainly by the conductive cooling. The residual geoid anomaly decay rate explains the efficiency of heat transmission processes that takes place in the young age oceanic lithosphere. The heat gain and loss processes of the lithosphere are well controlled owing to the near uniform distribution of heat sources and its thermal boundary layer. The near uniform distribution of hypocentral depths of around $10 \mathrm{~km}$ along the Carlsberg Ridge axial valley, also hints the relatively steady nature of energy releasing sources. The steadiness of the geoid anomaly rate also depends upon the growth of the thermal boundary layer, which approaches to greater depths at older ages. For the case of young oceanic lithosphere, this layer is well defined. The depth to the thermal boundary layer ' $Y_{L}$ ' for two profiles from the spreading Carlsberg Ridge are shown in figures 8(a) and 9(a). This has been calculated using cooling half-space model of Parsons and Sclater (1977), $Y_{L}=2.32 \sqrt{\kappa t}$ with the standard thermal diffusivity $\kappa=1 \mathrm{~mm}^{2} \mathrm{~s}^{-1}$. The conductive thermal boundary layer grows vertically as the plate moves away from the Mid-Ocean ridge axis owing to its progressive cooling. This, in fact, causes deepening of the sub-lithospheric mantle heat sources. The trend and fall in the thermal boundary layer from the ridge-spreading axis is correlatable with the residual geoid anomaly decay as shown earlier as red line in figure 4(c). At the ridge-spreading axis, the residual geoid anomaly is around $+3 \mathrm{~m}$ due to the ascension of the sub-lithospheric mantle from the thin low viscosity layer and falls to $-0.5 \mathrm{~m}$ as mantle descends at greater distances. The ascension of relatively denser sub-lithospheric mantle at the ridge axis would raise the sub-solidus temperature. 

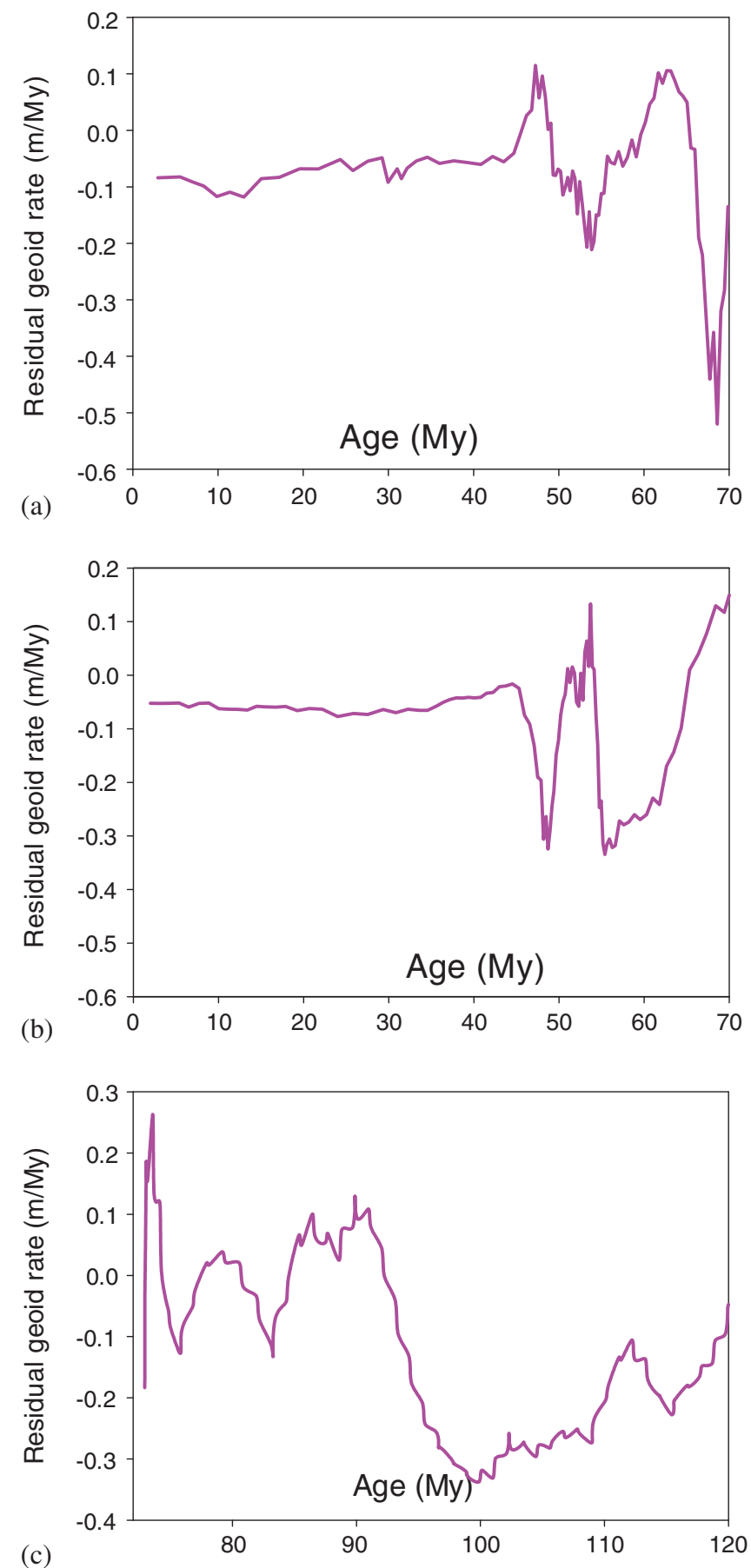

Figure 7. Variation of geoid anomaly decay rate with increase in lithospheric age. (a) and (b) show the steady residual geoid anomaly decay rate along profiles $\mathrm{AA}^{\prime}$ and $\mathrm{BB}^{\prime}$ (shown in figure 5), respectively for the case of youngaged Arabian Sea oceanic lithospheres. (c) shows the erratic geoid anomaly decay rate for the case of old-aged oceanic lithospheres in the Bay of Bengal as obtained for profile $\mathrm{CC}^{\prime}$ (shown in figure 6) represents the thermal instabilities.

The sub-solidus temperature is the difference in temperatures between the surface of the lithosphere and its thermal boundary layer, which can be calculated for the case of steady residual geoid anomaly decay rate for few profiles $\mathrm{AA}^{\prime}$ and $\mathrm{BB}^{\prime}$
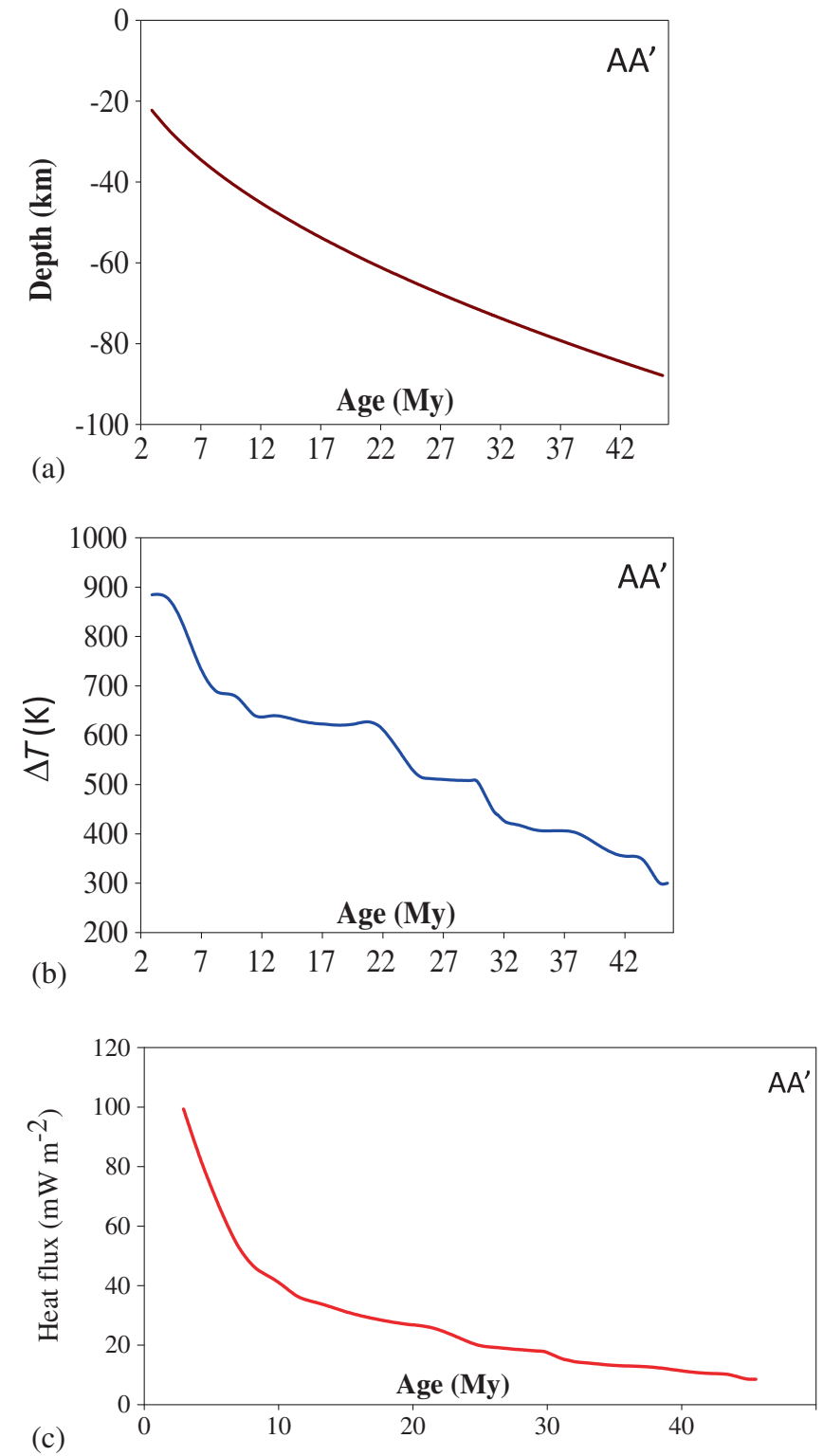

Figure 8. Variation of (a) thermal boundary layer, (b) basal temperature and (c) heat flux anomalies of young-aged oceanic lithosphere along profile $\mathrm{AA}^{\prime}$ with increase in lithospheric age and up to steady geoid decay rate; show the concurrence in their reduction in accordance with the residual geoid anomaly from the ridge axis. Heat flux varies from 10 to $100 \mathrm{~mW} \mathrm{~m}^{-2}$ from the ridge axis to higher lithospheric ages.

as shown in figure 5. However, we have seen from figure $7(\mathrm{a}-\mathrm{c})$ that for the case of old age $(>45 \mathrm{Ma})$ lithosphere, the erratic behaviour of the residual geoid anomaly decay rate cause corresponding erratic variation in the sub-solidus temperatures. The sub-solidus temperature $\Delta T$ has been calculated from the reduced form of cooling halfspace model(Cazenave et al. 1983) with the geoid anomaly decay rate $\Delta N / \Delta t$ as shown below:

$$
\Delta N / \Delta t \approx-2 \pi G / g \alpha \rho_{m} \Delta T \kappa,
$$



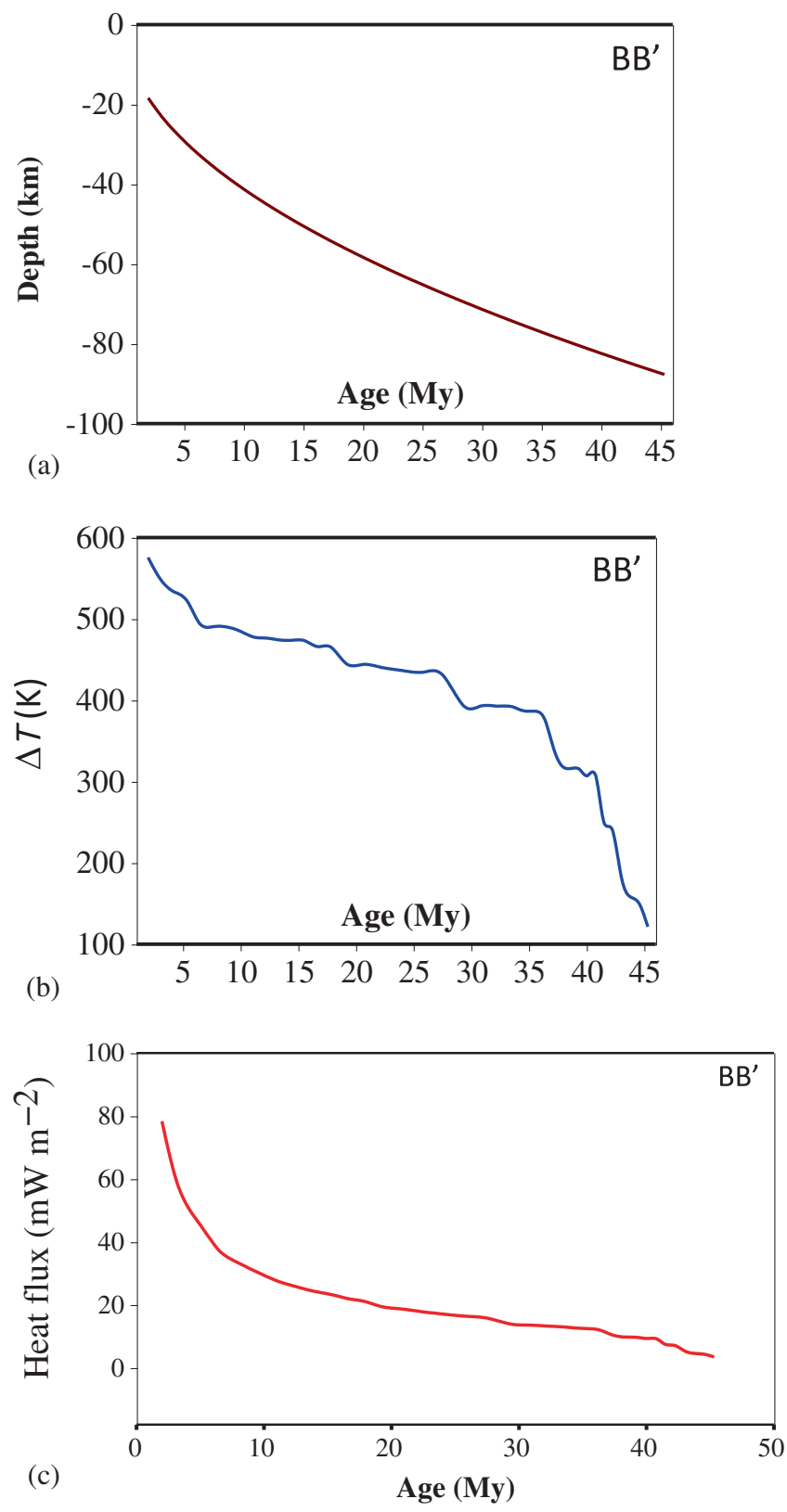

Figure 9. Variation of (a) thermal boundary layer, (b) basal temperature and (c) heat flux anomalies of young-aged oceanic lithosphere along profile $\mathrm{BB}^{\prime}$ with increase in lithospheric age and up to steady geoid decay rate; show the concurrence in their reduction in accordance with the residual geoid anomaly from the ridge axis. The heat flux variation is relatively less from 5 to $80 \mathrm{~mW} \mathrm{~m}^{-2}$.

where $\alpha=3 \times 10^{-5} \mathrm{~K}^{-1}$ is the coefficient of thermal expansion, $\rho_{m}=3300 \mathrm{~kg} \mathrm{~m}^{-3}$ is the mantle density, $\kappa=1 \mathrm{~mm}^{2} \mathrm{~s}^{-1}$ is the thermal diffusivity, $G=6.67259 \times 10^{-11} \mathrm{~m}^{3} \mathrm{~kg}^{-1} \mathrm{~s}^{-2}$ is the universal gravitational constant, $g=9.8 \mathrm{~m} \mathrm{~s}^{-2}$ is the acceleration due to gravity, $\Delta N=$ residual geoid variation along the profile and $\Delta t=$ crustal age variation along the concerned profile.

The residual geoid anomaly decay rates as shown in figure 7 ( $\mathrm{a}$ and $\mathrm{b})$ have been used to find the sub-solidus temperature of the young age oceanic lithosphere from the spreading axis of the Carlsberg Ridge to the regions where the geoid anomaly decay rate remains steady. The computed sub-solidus temperatures are shown in figures 8(b) and 9 (b). The fall of vertical temperature gradients from the axis of spreading centers toward greater lithospheric ages are evident, and the trends are analogues to the residual geoid anomaly. The range of temperature gradient is more for the case of westernmost profile $\mathrm{AA}^{\prime}$, where it is close to an active hydrothermal vent centre. For a progressively cooling oceanic lithosphere, conductive heat loss is a major heat transfer mechanism that leads to effective transfer of the heat energy from the near lithospheric mantle sources to the surface of cooling young age lithosphere. Thus, in order to find the heat flux variation with lithospheric age from the axis of spreading; one-dimensional Fourier heat conduction has been applied with average coefficient of thermal conductivity of Mid-Oceanic basalt of $3.0 \mathrm{~W} \mathrm{~m}^{-1} \mathrm{~K}^{-1}$ (Turcotte and Schubert 2002). The heat flux variations over the profiles are shown in figures 8(c) and 9(c). The westernmost profile $\left(\mathrm{AA}^{\prime}\right)$ has heat flux values range from 10 to $100 \mathrm{~mW} \mathrm{~m}^{-2}$, while the easternmost profile $\left(\mathrm{BB}^{\prime}\right)$ has variation from 5 to $80 \mathrm{~mW} \mathrm{~m}{ }^{-2}$. Both these profiles show maximum heat flux at the ridge axis, which falls rapidly by $10 \mathrm{Ma}$ and then gradually reduces with the increase of lithospheric age. The maximum heat flux values along both these profiles are $<150 \mathrm{~mW} \mathrm{~m}^{-2}$ (Pollack et al. 1993), which is the older estimate of the global mean heat flux of ocean ridge segments. However, the revised estimates of average heat flow over the oceans is around $60-80 \mathrm{~mW} \mathrm{~m}^{-2}$ based upon the high resolution heat flow data expanded up to harmonics degree 36 (Hamza et al. 2008). The computed average heat fluxes along the profiles $\mathrm{AA}^{\prime}$ and $\mathrm{BB}^{\prime}$ are 27.5 and $24 \mathrm{~mW} \mathrm{~m}^{-2}$, respectively, which is relatively less than the up-dated global mean estimates. The low heat flux values of the Carlsberg Ridge are indicative of the nature of its heat sources. It explains that the energy and mass sources of the Mid-Oceanic divergence of the Carlsberg Ridge need not be of convective origin as initiated from the lower mantle or from the plume. But from a shallower region near to the lithospheric mantle, where low heat and mass carrying convective cells arise owing to the temperature gradient between the lithosphere and the sub-lithospheric low-viscous thin layer. Craig and McKenzie (1986) have also proposed through numerical modelling, the existence of a thin low viscosity layer at the base of the lithosphere, where small scale convective cells can be generated. But the heat flux anomalies over the old-aged oceanic lithosphere are not evident mainly because of uncertainty in 
the process of conductive heat loss mechanism and hence on the formation of the thermal boundary layer. Thus, the computation of the basal heat flux anomalies over the ocean, especially for the youngaged oceanic lithospheres, from the satellite altimeter observed marine geoid and its residual anomaly components extracted from instantaneous sea surface height (SSH) measurements is a promising tool to study the Mid-Ocean Ridge activity, estimation of background heat flux of active and inactive spreading centers and the identification of possible heat anomaly sources, etc. The heat flux extraction methodology can be expanded further by applying two-dimensional Fourier analysis and hence, it will be possible to generate a map of background basal heat fluxes of young-aged oceanic lithospheres.

\section{Conclusions}

We attempted to constrain the marine geoid and its different wavelength constituents by correlating with earth's internal thermal processes and hence on the depth distribution of different mass density anomalies. The methodology for extracting different wavelength components of the residual marine geoid related with the past and the present lithospheric dynamics, plate cooling processes and basal heat flux variations of young and old-aged oceanic lithospheres in the northern Indian Ocean have been discussed.

Results show marked difference in the wavelength distribution, amplitude and limiting depth to the heat sources of young- and old-aged oceanic lithospheres in the northern Indian Ocean. The distribution of the residual geoid anomaly related with progressive cooling of young-aged oceanic lithosphere in the Arabian Sea basin with reference to the active Mid-Ocean Carlsberg Ridge, are in the shorter wavelength band of $111<\lambda<1900 \mathrm{~km}$ (21-360 harmonic band). But for the case of oldaged oceanic lithosphere in the BOB, the residual geoid anomaly cooling signals are not prominently seen in the same band as that of the Arabian Sea basin $(111<\lambda<1900 \mathrm{~km})$ because of the Ninetyeast Ridge magmatism (Rajesh and Majumdar 2014). The ridge magmatism corrupted the residual geoid thermal cooling anomaly signatures associated with the normal plate spreading of the $\mathrm{BOB}$ lithosphere. However, the BOB residual geoid thermal cooling signatures have been extracted in a relatively larger wavelength band of $1335 \leq \lambda \leq 3081$ $\mathrm{km}$, by considering the distribution of its lithospheric age and the expected fall in the residual geoid anomaly from its erstwhile spreading centers. The distinct, as well as, shorter and longer residual geoid anomaly bands of progressively cooling of young- and old-aged lithospheres of the Arabian Sea and the BOB, respectively, confirms the earlier marine magnetic anomaly interpretation of fast movement of the BOB basin during the middle Cretaceous prior to the India-Eurasia collision.

The difference in the residual geoid anomaly wavelength bands having cooling signatures of the young Arabian Sea and the old BOB lithospheres also constrain the limiting depths to their respective heat sources. In the BOB, the depth to the point mass anomaly is more and is in the range of 219-531 km, entirely confined to the upper mantle region. However, in the Arabian Sea basin, the depth to the point mass varies from 17 to 335 $\mathrm{km}$, even up to the shallow level of the oceanic crust. This, in fact, throws light on the nature of heat anomaly source and how it drives the young lithosphere from the spreading Carlsberg Ridge. The computed geoid anomaly decay rates for a young $(<45 \mathrm{Ma})$ aged lithosphere from the spreading Carlsberg Ridge with shallow heat anomaly sources appear steady, which shows conductive heat loss as a major mechanism that leads to its progressive cooling. The basal temperature change at the western portion, of the Carlsberg Ridge varies from 300 to $900 \mathrm{~K}$, where it is close to the vent at the ridge axis. But at its eastern portion, it varies from 150 to $580 \mathrm{~K}$. Similarly, the estimated basal heat flux which is also more (18-100 $\mathrm{mW} \mathrm{m}^{-2}$ ) at the western region of the ridge in comparison with the basal heat flux at its eastern region $\left(15-80 \mathrm{~mW} \mathrm{~m}^{-2}\right)$. The average heat fluxes at the western and eastern portions of the Carlsberg ridge are 27.5 and $24 \mathrm{~mW} \mathrm{~m}^{-2}$ respectively, which is less than the average basal heat fluxes of the oceanic lithospheres. Thus, for the young-aged oceanic lithosphere, the source of Mid-Ocean plate divergence is from the shallow near-lithospheric convective cells which originated from the thin low viscosity layer. The convective action is mainly controlled by the mass anomaly and temperature gradient between the lithosphere and the low viscosity thin sub-lithospheric mantle layer.

For the case of old-aged (>45 Ma) oceanic lithospheres both in the Arabian Sea and in the BOB, the geoid anomaly rates appear very conspicuous and erratic ( -0.3 to $0.2 \mathrm{~m} / \mathrm{Ma})$ and hence, have complicated heat loss and gain processes. The heat anomaly sources are mainly in the upper mantle region, where there are two possible sources; one that is related with plume remnant and the other because of disparity in the convective and conductive heat gain and loss processes of the aged lithosphere. In such cases, at the base of the lithosphere, the presence of non-sub-lithospheric convection having spatial wavelength ranging from hundreds to thousands of kilometers brings heat apart from the 
plume remnant sources and causes convective thermal instabilities and hence erratic geoid anomaly rates. The convective thermal instabilities affected the normal plate conductive cooling by supplying additional heat that would have accelerated the erstwhile India-Eurasia plate movement.

\section{Acknowledgements}

The authors are thankful to the Director, WIHG, Dehradun, and the Director, SAC (ISRO), Ahmedabad, for their keen interest in this study. They are also thankful for the critical comments of Prof. N V Chalapathi Rao, Assoc. Editor, and the anonymous referees which have helped in improving the manuscript. TJM wishes to thank CSIR, New Delhi for Emeritus Scientist Fellowship since January 2011.

\section{References}

Andersen O B, Knudsen P and Berry P A M 2010 The DNSC08GRA global marine gravity field from double retracked satellite altimetry; J. Geod. 84 191-199, doi: 10.1007/s00190-009-0355-9.

Beaulieu S E 2013 InterRidge Global Database of active submarine hydrothermal vent fields prepared for InterRidge, Version 3.1, http://vents-data.interridge.org.

Bowin C 1983 Depth of principal mass anomalies contributing to the Earth's geoidal undulations and gravity anomalies; Mar. Geod. 7 61-100.

Bowin C, Scheer E and Smith W 1986 Depth estimates from ratios of gravity, geoid, and gravity gradient anomalies; Geophys. 51(1) 123-136.

Bowin C 2000 Mass anomaly structure of the earth; Rev. Geophys. 38 355-387.

Cazenave A, Lago B and Dominh K 1983 Thermal parameters of the oceanic lithosphere estimated from geoid height data; J. Geophys. Res. 88 1105-1118.

Chase C G 1979 Subduction, the geoid and lower mantle convection; Nature 282 464-468.

Chatterjee S, Bhattacharyya R and Majumdar T J 2007 Utilization of high resolution satellite gravity over the Carlsberg Ridge; Mar. Geophys. Res. 28(4) 309-317, doi: 10.1007/s11001-007-9033-6.

Craig C H and McKenzie D 1986 The existence of a thinlow viscosity layer beneath the lithosphere; Earth Planet. Sci. Lett. 78 420-426.

Curray J R, Emmel F J, Moore D G and Raitt M W 1982 Structure, tectonics and geological history of the northeastern Indian Ocean; In: The ocean basin and margins (eds) Nairn A E M, Stehli F G and Uyeda S, The Indian Ocean (New York: Plenum Press) 6 399-449.

DeLaughter J, Stein S and Stein C A 1999 Extraction of a lithospheric cooling signal from oceanwide geoid data; Earth Planet. Sci. Lett. 174 173-181.

Dietz R S and Holden J C 1970 Reconstruction of Pangea: Breakup and dispersion of continents, Permian to present; J. Geophys. Res. 75 4939-4956.
Doin M P, Fleitout L and Mckenzie D 1996 Geoid anomalies and the structure of the continental and oceanic lithospheres; J. Geophys. Res. 101 16,119-16,135.

Hager B H, Clayton R W, Richards M A, Comer R P and Dziewonski A 1985 Lower mantle heterogeneity, dynamic topography, and the geoid; Nature 313 541-545.

Hamza V M, Cardoso R R and Ponte Neto C F 2008 Spherical harmonic analysis of earth's conductive heat flow; Int. J. Earth Sci. 97 205-226, doi: 10.1007/ s00531-007-0254-3.

Heiskanen W A and Moritz H 1967 Physical Geodesy; Freeman and Co., San Francisco.

Hofmeister A M and Criss E 2005 Earth's heat flux revised and linked to chemistry; Tectonophys. 395 159-177.

King S D 2002 Geoid and topography over subduction zones, the effect of phase transformations; J. Geophys. Res. 107 ETG 2-1-2-10.

Klootwijk C T 1984 A review of Indian Phanerozoic palaeomagnetism: Implications for the India-Asia collision; Tectonophys. 105 331-353.

Krishna K S, Neprochnov Y P, Rao G D and Grinko B N 2001 Crustal structure and tectonics of the Ninetyeast Ridge from seismic and gravity studies; Tectonics $\mathbf{3 0}(\mathbf{3})$ 416-433.

Lemoine F G et al. 1998 The development of the joint NASAGSFC and the National Imagery and Mapping Agency (NIMA) geopotential model EGM96; NASA/TP-1998206861: www.cddis.gsfc.nasa.gov.

Mahadevan T M 1994 Deep continental structure of India: A review; Geol. Soc. India Memoir 28 Bangalore, 569p.

Mahoney J J, Macdougall J D, Lugmair G W and Gopalan K 1983 Kerguelen hotspot source for Rajmahal traps and Ninetyeast Ridge? Nature 303 385-389.

Majumdar T J, Mohanty K K and Srivastava A K 1998 An atlas of satellite-derived gravity over the Indian offshore; ISRO-ONGC Joint Report SAC/RSAG/TR-01/98, SAC, Ahmedabad.

Muller R D, Roest W R, Royer J Y, Gahagan L M and Sclater J G 1997 Digital isochrons of the world's ocean floor; J. Geophys. Res. 102 3211-3214.

Parsons B and Sclater J G 1977 An analysis of the variation of ocean floor bathymetry and heat flow with age; J. Geophys. Res. 82 803-827.

Patriat P and Acache J 1984 India-Eurasia collision chronology has implications for crustal shortening and driving mechanism of plates; Nature 311 615-621.

Pollack H N, Hurter S J and Johnson J R 1993 Heat flow from the Earth's interior: Analysis of the global data set; Rev. Geophys. 31 267-280.

Rajesh S 2009 Geoid and the regional density anomaly field in the Indian Plate; Him. Geol. 30(2) 187-192.

Rajesh S and Majumdar T J 2003 Geoid generation and subsurface structure delineation under the Bay of Bengal, India using satellite altimeter data; Curr. Sci. 84(11) 1428-1436.

Rajesh S and Majumdar T J 2009 Lithospheric cooling and retrieval of basal heat flux anomalies of spreading Carlsberg Ridge from satellite altimeter derived geoid anomalies; Proc. 46th Annual convention of Indian Geophysical Union (IGU) on 'Evolution of Himalayan Foreland Basin and Emerging Exploration Challenges', Wadia Institute of Himalayan Geology, Dehradun, India, 5-7 October 2009, Paper no. 18, pp. 31-33.

Rajesh S and Majumdar T J 2010 Geoid height versus topography of the northern Ninetyeast Ridge: Implications on crustal compensation; Mar. Geophys. Res. 30 251-264, doi: 10.1007/s11001-010-9088-7.

Rajesh S and Majumdar T J 2014 Effects of Ninetyeast Ridge magmatism and pre-India-Eurasia collision 
dynamics on basement and crust-lithospheric structures of the northeastern Indian Ocean; J. Geol. Soc. India 84(5) 531-543.

Rajesh S, Majumdar T J and Krishna K S 2015 Lithospheric stretching and the long wavelength free-air gravity anomaly of the Eastern Continental Margin of India and the $85^{\circ}$ E Ridge, Bay of Bengal; Ind. J. Geomar. Sci. 44(6) $12 \mathrm{p}$.

Ramana M V et al. 1992 Marine magnetic studies in the northern Bay of Bengal, preliminary results; In: Oceanography of Indian Ocean (ed.) Desai B N (New Delhi: Oxford and IBH Publications), pp. 519-525.

Rao G D, Krishna K S and Sar D 1997 Crustal evolution and sedimentation history of the Bay of Bengal since the Cretaceous; J. Geophys. Res. 102 17,747-17,768.

Rapp R H 1986 Gravity anomalies and sea surface heights derived from a combined GEOS 3/Seasat altimeter data set; J. Geophys. Res. 91 4867-4876.

Ricard Y, Richards M A, Lithgow-Bertelloni C and Stunff Le Y 1993 A geodynamic model of mass heterogeneity; J. Geophys. Res. 98 21,895-21,909.

Richards M A and Hager B H 1984 Geoid anomalies in a dynamic earth; J. Geophys. Res. 89 59876002.

Royer J Y, Sclater J G and Sandwell D T 1989 A preliminary tectonic fabric chart of the Indian Ocean; Proc. Indian Acad. Sci. (Earth Planet. Sci.) 98(1) 7-24.
Sandwell D T and Smith W H F 1997 Marine gravity anomaly from Geosat and ERS-1 satellite altimetry; $J$. Geophys. Res. 102 10,039-10,054.

Singh D D 1990 Q-structure beneath the north and central Indian ocean from the inversion of observed Love and Rayleigh wave attenuation data; Phys. Earth Planet. Int. $59243-258$.

Smith W H F and Sandwell D T 1997 Global seafloor topography from satellite altimetry and ship depth soundings; Science 277 1957-1962.

Storchak D A, Giacomo D D, Bondár I, Engdahl E R, Harris J, Lee W H K, Villaseñor A and Bormann P 2013 Public Release of the ISC-GEM Global Instrumental Earthquake Catalogue (1900-2009); Siesmol. Res. Lett. 84(5) 810815, doi: $10.1785 / 0220130034$.

Subrahmanyam C, Thakur N K, Gangadhara Rao T, Khanna R, Ramana M V and Subrahmanyam V 1999 Tectonics of the Bay of Bengal: New insights from satellite-gravity and ship-borne geophysical data; Earth Planet. Sci. Lett. 171 237-251.

Torge W 1989 Gravimetry; Walter de Gruyter and Co., Berlin, 465p.

Turcotte S and Schubert G 2002 Geodynamics; 2nd edn (Cambridge: Cambridge University Press), 56p.

Wei M and Sandwell D T 2006 Estimates of heat flow from Cenozoic seafloor using global depth and age data; Tectonophys. 417 325-335. 